\title{
Screening of Wheat (Triticum aestivum L.) Genotypes for Lodging Tolerance Using Morpho-Physiological Traits
}

\author{
Kiran P. Bhagat", R. Arun Kumar, Poonam Kashyap, Archana Khadse, \\ Rupendra Kumar Jhade, S.R. Kushwaha and R.K. Sairam
}

ICAR-DOGR, Rajgurunagar-410505, Pune, India

*Corresponding author

\section{Keywords}

Chain weight, Lodging resistance factor index, Lodging tolerance, Stem breaking strength, Wheat

Article Info

Accepted:

12 March 2018

Available Online:

10 April 2018

\section{A B S T R A C T}

Lodging in winter wheat may cause serious losses in productivity, grain quality and harvest efficiency. To understand the lodging pattern with respect to morpho-physiological parameters, a field experiment was conducted at Research Farm, Indian Agricultural Research Institute, New Delhi, India during rabi season with 24 wheat genotypes and laid out in randomized block design (RBD) with three replications. Results indicated that morpho-physiological parameters, viz., the stem strength of lodging tolerant genotypes was significantly higher due to thicker stem and lower second internodal length compared to susceptible genotypes. Further, the stem strength was directly proportional to the lodging resistant factor index (LRFI). Yield and yield attributes were directly proportional to the Stem strength and LRFI as higher stem strength contributed significantly towards holding up of strong sink potential. Principal component analysis revealed that C 306 indicated greater second internodal length (SIL), leaf area (LA), plant height (PH) and lower LRFI, chain weight $(\mathrm{CW})$, harvest index $(\mathrm{HI})$, grain yield $(\mathrm{GY})$ and grain weight per ear (GWPE). GW 143 showed higher GY, HI and GWPE. HD 2934 indicated higher G No, while Raj showed the least. CW was recorded with better in D1 788-2.

\section{Introduction}

Lodging in cereals refers to the displacement of culm from an upright position. Lodging is the process in which shoots of cereals displace from vertical orientation (Rajkumara, 2008). Lodging has been studied more intensively in wheat for which a model of the lodging process has also been developed (Sterling et al., 2003). Lodging can be classified into two types, the first being stem lodging, which is the bending or breaking of the lower culm internodes. This depends on the tensile failure strength of the first internodes, as well as on stem wall diameter and thickness (Verma et al., 2005). The second is root lodging, which refers to the straight and intact culms leaning from the crown, involving a certain disturbance of the root system (Karim and Jahan, 2013).

Lodging occurs due to the interactions between plant, wind, rain and soil. Wind and rain exert a force which bends or breaks the stem base (stem lodging), or displaces the roots within the soil (root lodging) (Berry et 
al., 2000). Plant height has been the main target for the improvement of lodging resistance. Plant breeders have reduced lodging risk by introducing dwarfing genes to decrease plant height which is negatively correlating with lodging resistance, but the reduction in plant height to improve lodging resistance could reduce the photosynthetic capacity resulting reduction of yield (Zhang et al., 2017). What has not been achieved is good lodging resistance in all short spring wheats, nor a complete understanding of its physiological basis. New information is coming to light on the possible role of stored stem reserves at anthesis, for these reserves appear to have increased as yield potential has increased (Fischer, 2007).

In crops, lodging is caused by a loss of balance within the body of the plant. The lower part of the plant supports the heavier upper part, including the ear, leaves, and upper stem (Huang et al., 2006). Thus, reducing plant height, increasing pushing resistance, and increasing the weight of the lower stem are all important targets for improvement that could improve this balance and increase lodging resistance. The proportionality between the sturdiness of the lower part and the weight of the upper part determines the vulnerability of a given cultivar to lodging (Kashiwagi et al., 2005).

The tendency of a crop to lodge depends on the resistance of the lower internodes. This is because the lower internodes have to resist the greatest movement of force. The weight of the higher internodes of the stems plus leaves and heads in relation to the stem (culm) will affect the resistance of a crop to lodging. The heavier the higher parts of the stem are and the greater the distance from their centre of gravity to the base of the stem, the greater is the movement of the forces acting upon the lower internodes and the roots. Kelbert et al., (2004) reported that the breaking strength of the lowest internode and shoot / root ratio were the most suitable indices of lodging. Unfortunately, the determination of the stem strength is not perfect for wheat breeding and genetics up to now (Xiao et al., 2002). The aims and objective of the present research was to screen the wheat genotypes on the basis of physiological parameters for lodging tolerance and to group them in to lodging tolerant and susceptible one, and evaluate the degree of genetic relationship among genotypes.

\section{Materials and Methods}

A field experiment was conducted during the rabi season at the Research Farm, Division of Plant Physiology, Indian Agricultural Research Institute, New Delhi, India and the data were taken to analyze the physiological traits associated with lodging tolerance and then screening of wheat genotypes was done on the basis of morpho- physiological traits. Twenty four wheat genotypes obtained from Directorate of Wheat Research (DWR), Karnal were used for screening for lodging resistance. Plant height of five plants was measured from base of the plant to its tip and then average was taken. The leaves of five plants were collected and the leaf area per plant was recorded by automatic leaf area meter, LICOR-3000 (LICOR Ltd., Lincoln, Nebraska, USA) and average was calculated. Leaf area was directly obtained in $\mathrm{cm}^{2} /$ plant Leaf area of only green leaves was measured. Roots of the five sampled plants were cut and separated. Remaining parts i.e. leaves, stems and ears were sun-dried and then oven-dried at $65^{\circ} \mathrm{C}$ for $48 \mathrm{~h}$ and weighed on electric operated top pan balance (Mettler, Type K7T, Switzerland). The dry weight of individual components were recorded and added to obtain dry weight/plant. The internodes were numbered from top to bottom. The prostrate tester was set perpendicularly at the middle of the second internode of the plant. The stem strength was measured when the plant was 
pushed to an angle of 45 from the vertical and it was estimated using the following formula: Stem strength $(\mathrm{g} /$ stem $)=[($ test reading $\div 40) \times$ $(1000 \div$ number of stems)]. Second internodal length was measured in five plants and expressed in terms of $\mathrm{cm}$ and average was recorded. Chain weight was measured as the chain weight which balances with the bending strength of the stem (Cruz et al., 2005), and the unit was expressed as gram. LRFI was calculated by the ratio of chain weight to plant weight as given by Murphy et al., (1958), and multiplied by 100 to express on percentage basis. The threshed and cleaned grains from net plot of wheat were weighed and the grain yield is expressed in $\mathrm{g} / \mathrm{m}^{2}$. The grains from the sampled wheat ear heads were separated, counted and expressed as the number of grain/ear. One thousand grains were separated from the harvested produce of the wheat from each plot and their weight in $g$ was expressed as 1,000 grain weight. Harvest index was computed as the ratio of grain yield to the total biological yield multiplied by 100 to express on percentage basis.

The data collected on different parameters were subjected to statistical analysis following the procedure described by Cochran and Cox (1957). The critical difference (CD) was worked out where analysis of variance was found significant for treatment effect. The treatment effects were tested at 5\% probability level for their significance. Principal component analysis (PCA) and hierarchical clustering (HC) were used to display the correlations between the various physiological traits and their relationship with the twenty four wheat genotypes. PCA and HC analysis was carried out using the JMP Genomicsversion 6.0.

\section{Results and Discussion}

Lodging is one of the major yield limiting factors of cereals. Plant height is one of the important factors, for the improvement of lodging resistance in wheat (Keller et al., 1999). Our results indicated wide range of variation in plant height among tall, mediumtall and semi-dwarf wheat genotypes, ranging from $72.2 \mathrm{~cm}$ in case of Raj-3765 to $116.3 \mathrm{~cm}$ as in C-306. The various morphophysiological parameters such as plant height, leaf area, stem strength, $2^{\text {nd }}$ - intermodal length, chain weight and LRFI were recorded at 80 days after sowing in wheat genotypes (Table 1).

Yield and yield attributes were recorded (Table 2) and significant differences were noted among tall, medium-tall and semi-dwarf genotypes. Among the genotypes, WH-730 recorded the highest grain yield $\left(365.7 \mathrm{~g} / \mathrm{m}^{2}\right)$, while C-306 recorded the lowest grain yield $\left(154.4 \mathrm{~g} / \mathrm{m}^{2}\right)$. However, non-significant differences were observed within each group, viz., the tall, medium-tall and semi-dwarf. Further, semi-dwarf genotypes showed higher harvest index (42.89\%) whereas tall genotypes recorded significantly lower harvest index $(22.12 \%)$ among the groups. GW-143 recorded the highest harvest index $(44.68 \%)$, while $\mathrm{C}-306$ recorded the lowest harvest index (20.74\%).

Plant height was found to be negatively correlated with lodging resistance (Table 3). Similar results were reported by Min (2001). Flintham et al., (1997) observed that in wheat plant height between $70 \mathrm{~cm}$ and $100 \mathrm{~cm}$ was best for maximum photosynthetic capacity in a canopy. Though, the plant height was positively correlated with total dry weight, it was negatively correlated with stem strength, chain weight, LRFI, grain yield and harvest index. Semi-dwarf genotypes, which have significantly lower plant height, also have higher lodging resistance as compared with medium-tall and tall genotypes. Further, Min (2001) reported that there was strong correlation between plant height and lodging. 
Leaf area did not vary much within the groups, whereas it differed significantly among the groups. Leaf area of tall genotypes was significantly higher than the medium-tall and semi-dwarf genotypes and negatively correlated with stem strength, chain weight and LRFI.

Stem is one of the most important plant organs playing a key role in transportation, storage and mechanical strength. Stem strength has a vital role in lodging resistance (Han, 1990). Our results showed that higher stem strength in semi-dwarf compared with medium-tall and tall genotypes. The stem strength also indicated positive correlations with chain weight, LRFI, grain yield, grain weight and harvest index. The results obtained are in conformity with Zhang et al., 2017. The second- internodal length of dwarf genotypes was significantly lower than the tall genotypes at all the growth stages. This is in conformity with the results obtained by Xiao et al., (2002), who also observed that the basal internode was significantly correlated with stem strength in wheat.

Chain weight indicated the strength of the plant and with the help of this parameter; we can easily work out LRFI (Huang, 1988). This index showed the ability of plant to resist lodging. Higher the index value higher will be the lodging resistance. Chain weight of semidwarf genotypes was significantly higher than the medium- tall and tall genotypes at all the stages.

LRFI was significantly higher in semi-dwarf genotypes as compared to tall and medium-tall genotypes. The chain weight was significantly correlated with LRFI, grain yield, grain weight and harvest index but it was negatively correlated with plant height.

Principal component analysis clearly indicates correlation between various physiological parameters and their relationship in different wheat genotypes. The principal component analysis (PCA) and their correlation are shown in Figure 1a. The principal component 1 (PC1) represents 77 per cent of variability, while the PC2 represents 12.2 per cent of variability among the data. Almost all parameters were occupied on the both sides of the biplot and among the parameters the GWPE, G.No, SIL, LA, P.H, and TDDM occupied at left side, while Tw, SSt, LRFI, CW, HI, and GY was observed at right side of the biplot. Biplot indicates that GWPE, G.No, SIL, LA are having positive correlation among themselves, while Tw, SSt and LRFI showed higher positive correlation between themselves. GWPE, G.No, SIL, LA and P.H showed significant negative correlation with GY, HI, CW, LRFI, SSt.

Principal component analysis revealed that twenty four wheat genotypes were found in clusters in biplots (Fig. 1b). The Raj-3765, Raj-4014, HD-2687, NW-2036, DL-788-2, K2008, PBW-502, 9CHT-16, WH-896, PBW503, WH-730, HD-2329, LOK-1 GW-143and PBW-175 were observed at right side of biplot, while HD-2913, HD-2934, HI-1535, HI-1479, HI-1418, HI-1454, HI-1531, RR-3 and C-306 was observed at left side of biplot.

The interpretation of the PCA results can be explained by positioning of the wheat genotypes and physiological parameters by superimposition of respective PCA plots (Fig. $1 \mathrm{a}$ and $1 \mathrm{~b}$ ).

Superimposition showed that PBW 503 possessed higher SSt, while RR 3 shown the least. C 306 indicated greater SIL, LA, PH and lower LRFI, CW, HI, GY and GWPE. GW 143 showed higher GY and HI. HD 2934 indicated higher G No, while Raj 4014 showed the least. Tw and TDDM were found higher in K 2008 and RR 3 respectively. CW was recorded higher in D1 788-2. 
Table.1 Morpho-physiological parameters at 80 days after sowing in wheat genotypes

\begin{tabular}{|c|c|c|c|c|c|c|}
\hline Genotypes & $\begin{array}{c}\text { Plant } \\
\text { height } \\
\text { (cm) }\end{array}$ & $\begin{array}{l}\text { Leaf } \\
\text { Area } \\
\left(\mathrm{cm}^{2}\right)\end{array}$ & $\begin{array}{l}\text { Stem } \\
\text { strength } \\
\text { (g) }\end{array}$ & $\begin{array}{c}2^{\text {nd }} \text { internodal } \\
\text { length (g) }\end{array}$ & $\begin{array}{c}\text { Chain weight } \\
\text { (g) }\end{array}$ & $\begin{array}{l}\text { LRFI } \\
(\%)\end{array}$ \\
\hline \multicolumn{7}{|c|}{ Semi-dwarf genotypes } \\
\hline HD-2329 & 78.2 & 65.6 & 10.68 & 10.8 & 50.2 & 74.70 \\
\hline WH-896 & 83.0 & 97.3 & 11.89 & 8.5 & 51.8 & 68.70 \\
\hline PBW-503 & 83.1 & 92.1 & 12.13 & 8.2 & 51.4 & 69.00 \\
\hline $\mathrm{K}-2008$ & 80.8 & 73.9 & 10.00 & 11.8 & 52.4 & 73.40 \\
\hline DL-788-2 & 80.4 & 77.3 & 10.13 & 10.7 & 52.7 & 72.50 \\
\hline 9CHT-16 & 82.0 & 88.3 & 10.60 & 8.5 & 52.1 & 70.90 \\
\hline GW-143 & 85.4 & 109.7 & 8.85 & 10.8 & 50.3 & 67.80 \\
\hline Raj-4014 & 74.7 & 57.8 & 10.25 & 10.8 & 49.5 & 75.60 \\
\hline NW-2036 & 80.3 & 71.8 & 9.65 & 11.2 & 52.4 & 74.00 \\
\hline PBW-502 & 81.3 & 86.8 & 11.05 & 10.2 & 51.0 & 71.60 \\
\hline Raj-3765 & 72.2 & 53.2 & 11.59 & 9.3 & 49.4 & 76.30 \\
\hline WH-730 & 84.7 & 103.5 & 10.67 & 10.2 & 51.3 & 68.10 \\
\hline LOK-1 & 81.7 & 80.2 & 10.12 & 11.3 & 51.9 & 72.10 \\
\hline PBW-175 & 82.2 & 89.3 & 10.67 & 10.5 & 52.4 & 70.20 \\
\hline HD-2687 & 76.1 & 58.1 & 9.88 & 10.5 & 49.4 & 75.20 \\
\hline Mean & 80.41 & 80.33 & 10.54 & 10.22 & 51.23 & 72.01 \\
\hline \multicolumn{7}{|c|}{ Medium-tall genotypes } \\
\hline HI-1535 & 92.4 & 208.1 & 9.21 & 12.5 & 36.2 & 44.07 \\
\hline HI-1531 & 97.9 & 245.9 & 7.40 & 11.7 & 34.8 & 40.80 \\
\hline HI-1479 & 90.4 & 198.7 & 9.35 & 11.0 & 36.1 & 44.17 \\
\hline HI-1454 & 95.6 & 234.7 & 10.55 & 10.0 & 35.6 & 42.10 \\
\hline HI-1418 & 94.8 & 226.5 & 10.65 & 9.7 & 35.5 & 43.30 \\
\hline Mean & 94.22 & 222.78 & 9.43 & 10.97 & 35.65 & 42.89 \\
\hline \multicolumn{7}{|c|}{ Tall genotypes } \\
\hline $\mathrm{C}-306$ & 116.3 & 295.0 & 7.81 & 16.5 & 22.4 & 21.70 \\
\hline HD-2934 & 109.0 & 257.3 & 7.85 & 16.0 & 23.4 & 24.03 \\
\hline RR-3 & 114.9 & 283.9 & 6.72 & 15.9 & 22.6 & 22.50 \\
\hline HD-2913 & 111.2 & 272.4 & 7.87 & 14.5 & 23.2 & 23.30 \\
\hline Mean & 112.85 & 277.14 & 7.56 & 15.73 & 22.92 & 22.88 \\
\hline Total Mean & 95.83 & 193.42 & 6.78 & 12.31 & 36.60 & 45.93 \\
\hline CD at $5 \%$ & 13.8 & 50.1 & 1.92 & 1.78 & 7.38 & 8.2 \\
\hline
\end{tabular}


Table.2 Yield and yield attributes at harvest in wheat genotypes

\begin{tabular}{|c|c|c|c|c|c|}
\hline Genotypes & $\begin{array}{l}\text { Grain yield } \\
\qquad\left(\mathrm{g} \mathrm{m}^{-2}\right)\end{array}$ & $\begin{array}{c}\text { Grain } \\
\text { number per } \\
\text { ear }\end{array}$ & $\begin{array}{l}\text { Grain } \\
\text { weight per } \\
\text { ear }\end{array}$ & Test weight & $\begin{array}{c}\text { Harvest } \\
\text { index }(\%)\end{array}$ \\
\hline \multicolumn{6}{|c|}{ Semi-dwarf genotypes } \\
\hline HD-2329 & 355.6 & 40.3 & 1.55 & 40.4 & 43.45 \\
\hline WH-896 & 363.8 & 45.3 & 2.00 & 45.4 & 44.57 \\
\hline PBW-503 & 362.5 & 45.3 & 1.99 & 45.4 & 44.21 \\
\hline K-2008 & 344.8 & 42.7 & 1.95 & 50.4 & 42.41 \\
\hline DL-788-2 & 347.5 & 44.7 & 1.91 & 44.2 & 42.81 \\
\hline 9CHT-16 & 359.6 & 44.0 & 1.89 & 44.4 & 43.86 \\
\hline GW-143 & 369.7 & 43.7 & 1.80 & 43.6 & 44.68 \\
\hline Raj-4014 & 316.3 & 40.0 & 1.90 & 49.7 & 41.16 \\
\hline NW-2036 & 338.5 & 44.0 & 2.09 & 48.1 & 42.29 \\
\hline PBW-502 & 333.1 & 43.7 & 2.02 & 48.1 & 41.60 \\
\hline Raj-3765 & 307.4 & 41.0 & 1.88 & 47.9 & 40.90 \\
\hline WH-730 & 365.7 & 41.3 & 1.63 & 41.2 & 44.61 \\
\hline LOK-1 & 352.4 & 41.7 & 1.63 & 41.5 & 42.86 \\
\hline PBW-175 & 360.6 & 42.0 & 1.73 & 42.0 & 44.23 \\
\hline HD-2687 & 321.2 & 45.3 & 2.01 & 46.6 & 41.53 \\
\hline Mean & 346.58 & 43.00 & 1.87 & 45.26 & 43.01 \\
\hline \multicolumn{6}{|c|}{ Medium-tall genotypes } \\
\hline HI-1535 & 279.8 & 49.7 & 2.14 & 44.7 & 36.15 \\
\hline HI-1531 & 253.1 & 45.0 & 1.82 & 41.3 & 32.22 \\
\hline HI-1479 & 285.1 & 44.0 & 1.91 & 44.8 & 37.68 \\
\hline HI-1454 & 262.4 & 44.3 & 1.77 & 41.5 & 33.11 \\
\hline HI-1418 & 267.0 & 47.0 & 1.98 & 43.9 & 34.75 \\
\hline Mean & 269.48 & 46.00 & 1.92 & 43.24 & 34.78 \\
\hline \multicolumn{6}{|l|}{ Tall genotypes } \\
\hline C-306 & 154.4 & 51.3 & 1.84 & 37.6 & 20.74 \\
\hline HD-2934 & 182.0 & 54.7 & 2.10 & 40.2 & 21.69 \\
\hline RR-3 & 167.2 & 52.0 & 1.93 & 38.6 & 23.64 \\
\hline HD-2913 & 171.3 & 52.0 & 1.95 & 38.1 & 22.41 \\
\hline Mean & 168.73 & 52.50 & 1.96 & 38.63 & 22.12 \\
\hline Total Mean & 261.60 & 47.17 & 1.91 & 42.38 & 33.30 \\
\hline CD at $5 \%$ & 17.22 & 14.34 & 0.18 & 9.68 & 14.42 \\
\hline
\end{tabular}


Table.3 Correlations between different traits in wheat genotypes

\begin{tabular}{|c|c|c|c|c|c|c|c|c|c|c|c|c|}
\hline Character & GY & SSt & PH & $\mathbf{L A}$ & SIL & Ch W & LRFI & TDDM & GNo & GWPE & $\mathbf{T w}$ & HI \\
\hline GY & 1.000 & & & & & & & & & & & \\
\hline SSt & $0.766^{* *}$ & 1.000 & & & & & & & & & & \\
\hline PH & $-0.906^{* *}$ & $-0.781^{* *}$ & 1.000 & & & & & & & & & \\
\hline LA & $-0.899^{* *}$ & $-0.733^{* *}$ & $0.957^{* *}$ & 1.000 & & & & & & & & \\
\hline SIL & $-0.836^{* *}$ & $-0.872^{* *}$ & $0.813^{* *}$ & $0.704^{* *}$ & 1.000 & & & & & & & \\
\hline ChW & $0.973^{* *}$ & $0.770^{* *}$ & $-0.946^{* *}$ & $-0.962^{* *}$ & $-0.802^{* *}$ & 1.000 & & & & & & \\
\hline LRFI & $0.935^{* *}$ & $0.757^{* *}$ & $-0.973^{* *}$ & $-0.989^{* *}$ & $-0.770^{* *}$ & $0.986^{* *}$ & 1.000 & & & & & \\
\hline TDDM & $-0.749^{* *}$ & $-0.760^{* *}$ & $0.929^{* *}$ & $0.873^{* *}$ & $0.725^{* *}$ & $-0.837^{* *}$ & $-0.886^{* *}$ & 1.000 & & & & \\
\hline GNo & $-0.825^{* *}$ & $-0.671^{* *}$ & $0.868^{* *}$ & $0.806^{* *}$ & $0.751^{* *}$ & $-0.845^{* *}$ & $-0.856^{* *}$ & $0.793^{* *}$ & 1.000 & & & \\
\hline GWPE & -0.268 & -0.121 & 0.160 & 0.181 & 0.147 & -0.230 & -0.218 & 0.079 & $0.536^{*}$ & 1.000 & & \\
\hline $\mathrm{Tw}$ & $0.582^{*}$ & $0.559^{*}$ & $-0.755^{* *}$ & $-0.689^{* *}$ & $-0.577^{*}$ & $0.658^{* *}$ & $0.696^{* *}$ & $-0.762^{* *}$ & $-0.534^{*}$ & 0.398 & 1.000 & \\
\hline HI & $0.991^{* *}$ & $0.778^{* *}$ & $-0.935^{* *}$ & $-0.910^{* *}$ & $-0.857^{* *}$ & $0.974^{* *}$ & $0.948^{* *}$ & $-0.784^{* *}$ & $-0.854^{* *}$ & -0.244 & $0.636^{* *}$ & 1.000 \\
\hline
\end{tabular}

*, ** significant at $\mathrm{P}=0.05$ and $\mathrm{P}=0.01$ level, respectively

Abbreviations

GY- Grain yield, SSt- Stem strength, PH- Plant height, LA- Leaf area, SIL - Second internode length, Ch W- Chain weight, LRFI- Lodging resistant factor index, TDDM- Total dry matter per plant, GNo- Grain number, GWPE - Grain weight per ear, Tw- Test weight and HI- Harvest index. 
Fig.1 (a) Loading biplot of physiological traits of wheat genotypes with PC1-PC2. A Correlation between 12 measured parameters, Parameter codes GWPE - Grain weight per ear, G.No- Grain number, SIL - Second internode length, LA- Leaf area, P.H- Plant height, TDDM- Total dry matter per plant, GY- Grain yield, HI- Harvest index, Ch W-Chain weight, LRFI- Lodging resistant factor index, SSt- Stem strength and Tw- Test weight

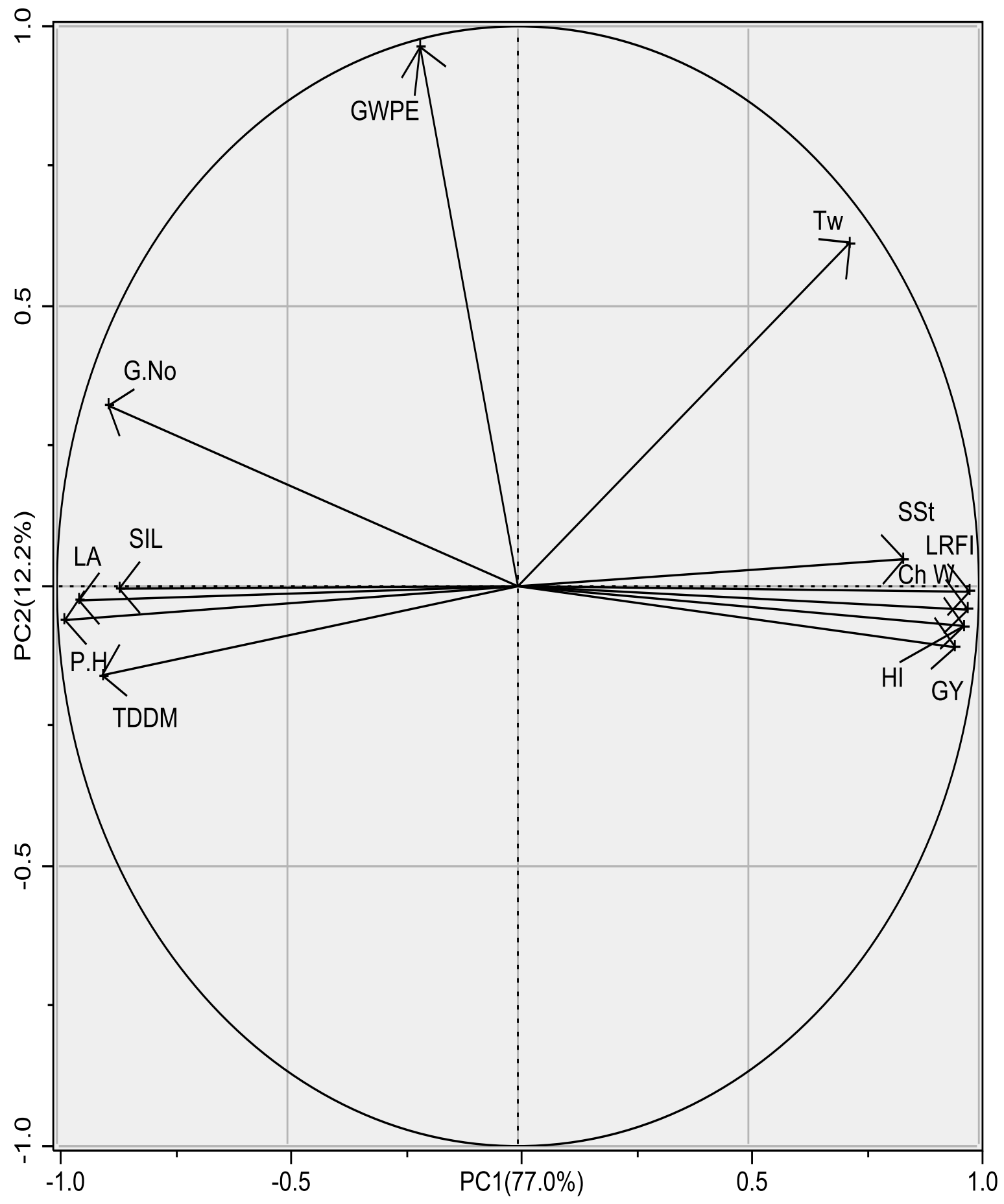


Fig.1 (b) Score biplot of wheat genotypes with PC1-PC2. Parameter codes: Wheat genotypes: Raj-3765, Raj-4014, HD-2687, HD-2329, NW-2036, DL-788-2, K-2008, PBW-502, LOK-1, 9CHT-16, PBW-175, WH-896, PBW-503, WH-730, GW-143, HI-1479, HI-1535, HI-1418, HI1454, HI-1531, HD-2934, HD-2913, RR-3 and C-306

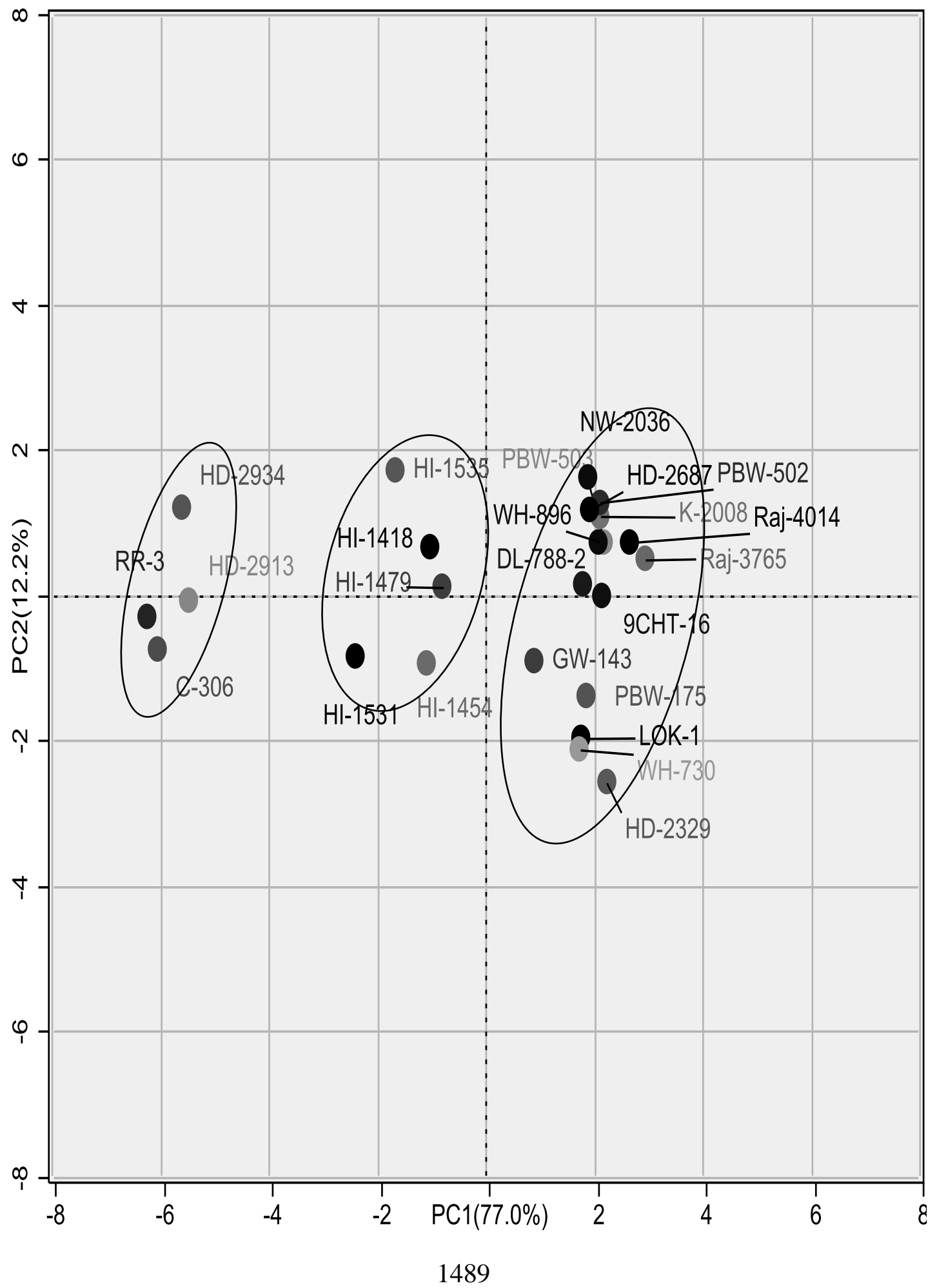


Fig.2 Two way hierarchical clustering (HC) between twenty four wheat genotypes on the basis of twelve measured parameters using ward method. Parameter codes GWPE - Grain weight per ear, G.No- Grain number, SIL - Second internode length, LA- Leaf area, P.H- Plant height, TDDM- Total dry matter per plant, GY- Grain yield, HI- Harvest index, Ch W- Chain weight, LRFI- Lodging resistant factor index, SSt- Stem strength and Tw- Test weight

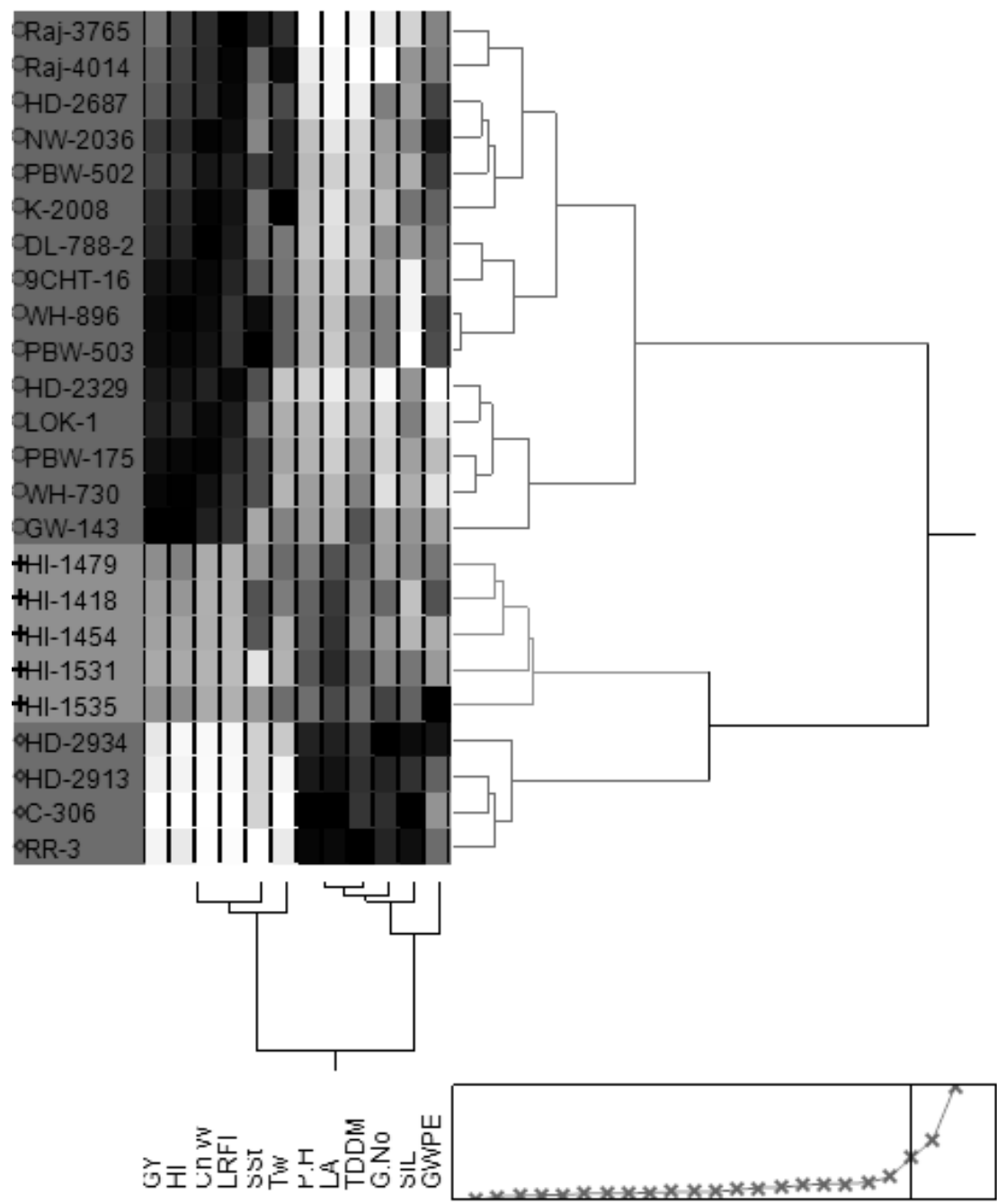

Hierarchical clustering (HC) analysis using ward method revealed that twenty four wheat genotypes fall in to two major clusters (Fig. 2). Cluster I included fifteen wheat genotypes in three groups, group I included Raj 3765, Raj 4014, K 2008, HD 2687, NW 2036, PBW 502 and group II includes DL 788-2, 9CHT16, WH-896, PBW 503 and group III includes HD 2329, LOK-1 PBW 175, WH 730, GW 143, while Cluster II included five wheat genotypes in two groups, HI 1535, HI 1479,
HI 1418, HI 1454, HI 1531 in one group and HD 2934, RR 3, HD 2913, C 306 in another group. Both the PCA and $\mathrm{HC}$ results corroborate each other i.e., the semi-dwarf genotypes, medium-tall and tall genotypes were grouped separately in three clusters.

Our results indicated that semi-dwarf genotypes showed significant differences over medium-tall and tall genotypes in relation to yield and yield components such as grain 
yield, test weight and harvest index. This was mainly due to higher lodging resistance in semi-dwarf genotypes. This is in conformity with the results obtained by Kono (1995). He also inferred that lodging resulted in significant loss in yield, quality of grain and the efficiency of mechanical harvesting.

On the basis of results obtained in this investigation we have concluded and grouped the used wheat genotypes into lodging tolerant and susceptible, mainly on the basis of plant height, stem strength and LRFI. On the other hand, the susceptible genotypes had advantage in terms of higher biomass. This trait is required to be incorporated into tolerant genotypes to enhance productivity potential of leading wheat genotypes. Stem strength and LRFI along with the plant height are vital consideration for breeding programs to accomplish the objective of getting lodging tolerant wheat genotypes.

\section{Acknowledgement}

We are grateful to the Indian Agricultural Research Institute, New Delhi for providing field and laboratory facilities for experiment and proper guidance. We also thank to the Indian Council of Agricultural Research for financial support.

\section{References}

Berry, P.M., Griffin, J.M., Sylvester-Bradley, R., Scott, R.K., Spink, J.H. and Baker, C.J., 2000. Controlling plant form through husbandry to minimise lodging in wheat. Field Crops Research, 67(1): 59-81.

Cochran, W.G. and Cox, G.M., 1957. Experimental Designs. In: John Willey \& Sons (II ${ }^{\text {nd }}$ edn.), Inc. 53, pp. 43-50.

Cruz, P.J., Silva, J.A., Carvalho, F.I., Oliveira, A.C., Benin, G., Vieira, E.A., Schmidt, D.A., Finatto, T., Ribeiro, G. and Fonseca, D.A., 2005. Genetics of lodging resistance in wheat. Crop Breeding and Applied Biotechnology, 5: 111-117.

Fischer, R.A., 2007. Understanding the physiological basis of yield potential in wheat. Journal of Agricultural Science, 145(2), 99-113.

Flintham, J.E., Borner, A., Worland, A.J. and Gale, M.D., 1997. Optimizing wheat grain yield: Effects of $R h t$ (gibberelline insensitive) dwarfing genes. Journal of Agricultural Science, 128: 11-25.

Han, Q.R. (1990). The relationship between the lodging and the morphological structure of the basal stems. Beijing Journal of Agricultural Science, 3: 1013.

Huang, X.Q., Cloutier, S., Lycar, L., Radovanovic, N., Humphreys, D.C., Noll, J.S., Somers, D.J. and Brown, P.D., 2006. Molecular detection of QTLs for agronomic and quality traits in a doubled haploid population derived from two Canadian wheats (Triticum aestivum L.). Theoretical and Applied Genetics, 113: 753-766.

Huang, Y.L., 1988. Morphological factors and control techniques of lodging in wheat. Jiangsu Journal of Agricultural Science, 10: 5-8.

Karim, M.D.H. and Jahan, M.A., 2013. Study of lodging resistance and its associated traits in bread wheat. ARPN Journal of Agricultural and Biological Science, 8(10): 683-687.

Kashiwagi, T., Sasaki, H. and Ishimaru, K., 2005. Factors responsible for decreasing sturdiness of the lower part in lodging of rice (Oryza sativa L.). Plant Production Science, 8(2): 166-172.

Kelbert, A.J., Spaner, D., Briggs, K.G. and King, J.R., 2004. The association of culm anatomy with lodging susceptibility in modern spring wheat genotypes. Euphytica, 136: 211-221. 
Keller, M., Karutz, C.H., Schmid, J.E., Stamo, P., Winzeler, M., Keller, B. and Messmer, M.M., 1999. Quantitative trait loci for lodging resistance in a segregating wheat $\times$ spelt population. Theoretical and Applied Genetics, 98: 1171-1182.

Kono, M., 1995. Physiological aspects of lodging. In: Matsuo, T.K. Kumazawa, R., Ishii, K. and Ishihrar, H. (eds). Science of the Rice Plant 2: Physiology, Food and Agriculture Policy Research Center, Tokyo, pp. 971-982.

Min, D.H., 2001. Studies on the lodging resistance with its subtraits of different height wheat varieties and correlation between plant height and yield. Journal of Triticeae Crops, 21(4): 76-79.

Murphy, H.C., Petr, F. and Frey, K.J., 1958. Lodging resistance studies in oats. Agronomy Journal, 50: 609-611.

Rajkumara, S., 2008. Lodging in cereals - a review. Agricultural Reviews, 29(1): 5560.
Sterling, M., Baker, C.J., Berry, P.M. and Wade, A., 2003. An experimental investigation of the lodging of wheat. Agricultural and Forest Meteorology, 119: 149-165.

Verma, V., Worland, A.J., Sayers, E.J., Fish, L., Caligari, P.D.S. and Snape, J.W., 2005. Identification and characterization of quantitative trait loci related to lodging resistance and associated traits in bread wheat. Plant Breeding, 124: 234-241.

Xiao, S.H., Zhang, X.Y., Yan, C.S., Zhang, W.X., Hai, L. and Guo, H.J., 2002. Determination of resistance to lodging by stem strength in wheat. Agricultural Sciences in China, 35(1): 7-11.

Zhang, M., Wang, H., Yi, Y., Ding, J., Zhu, M., Li, C., Guo, W., Feng, C. and Zhu, X., 2017. Effect of nitrogen levels and nitrogen ratios on lodging resistance and yield potential of winter wheat (Triticum aestivum L.). Plos One, 12(11): 1-17.

\section{How to cite this article:}

Kiran P. Bhagat, R. Arun Kumar, Poonam Kashyap, Archana Khadse, Rupendra Kumar Jhade, S.R. Kushwaha and Sairam, R.K. 2018. Screening of Wheat (Triticum aestivum L.) Genotypes for Lodging Tolerance Using Morpho-Physiological Traits. Int.J.Curr.Microbiol.App.Sci. 7(04): 1481-1492. doi: https://doi.org/10.20546/ijcmas.2018.704.167 